\title{
CINÉTICA DE ABSORÇÃO DE FÓSFORO E CRESCIMENTO DO SISTEMA RADICULAR DE GENÓTIPOS DE MILHO CONTRASTANTES PARA EFICIÊNCIA A FÓSFORO
}

\author{
VERA MARIA CARVALHO ALVES ${ }^{1}$, SIDNEY NETTO PARENTONI ${ }^{1}$, CARLOS ALBERTO \\ VASCONCELLOS ${ }^{1}$, GILSON VILLAÇA EXEL PITTA ${ }^{1}$, CARLA CRISTINA DE MOURA FRANÇA ${ }^{2}$ \\ ${ }^{1}$ Pequisadores, Embrapa Milho e Sorgo, Caixa Postal 151, CEP.35701-970 Sete Lagoas, MG. E-mail: \\ vera@cnpms.embrapa.br (autor para correspondência). \\ ${ }^{2}$ Bolsista da FAPEMIG.
}

Revista Brasileira de Milho e Sorgo, v.1, n.1, p.85-92, 2002

\begin{abstract}
RESUMO- Com o objetivo de estudar o efeito da omissão de P no meio de cultura nas características fisiológicas de absorção de $\mathrm{P}$ e no comprimento de raízes de oito genótipos de milho, quatro previamente classificados como eficientes e quatro como ineficientes para $P$, foram desenvolvidos dois experimentos. No primeiro, sementes dos oito híbridos de milho foram germinadas em rolos de papel-toalha e transplantadas para recipientes de plástico contendo solução nutritiva completa de Steinberg, $\mathrm{pH}$ 5,5. Sete dias após o transplante, o P foi retirado de metade das bandejas. Após três dias de omissão de $\mathrm{P}$, realizou-se a cinética de absorção de $\mathrm{P}$, iniciando-se a retirada de alíquotas de $10 \mathrm{ml}$ de cada vaso, a cada 30 minutos, durante oito horas. No segundo experimento, aos seis dias após a omissão do P no meio de cultivo, raízes das plantas dos tratamentos com e sem omissão de fósforo foram coletadas para avaliação do comprimento total do sistema radicular. A omissão de fósforo por três dias aumentou significativamente a velocidade máxima de absorção de fósforo (Vmax) e a taxa de influxo em seis genótipos de milho, quatro ineficientes e dois eficientes para P. O Km (Constante de Michaelis) foi significativamente modificado pela omissão de fósforo em apenas dois genótipos. Conclui-se que aumentos na Vmax e taxa de influxo de $\mathrm{P}$ com a omissão de $\mathrm{P}$ no meio de cultivo é um mecanismo geral de resposta das plantas à deficiência de $\mathrm{P}$, mas que não confere eficiência diferencial entre genótipos de milho. A omissão de P na solução nutritiva, por seis dias, aumentou significativamente o comprimento radicular em três dos genótipos eficientes para P. Nos genótipos ineficientes para P, não houve modificação significativa dessas características, indicando que o crescimento diferencial do sistema radicular pode ser um dos possíveis mecanismos da eficiência para fósforo em milho.
\end{abstract}

Palavras-chave: Zea mays L., estresse de fósforo, adaptação a solos ácidos, eficiência nutricional, absorção de fósforo.

\section{KINETIC PARAMETERS OF PHOSPHORUS UPTAKE AND GROWTH OF ROOT SYSTEM IN CONTRASTING MAIZE GENOTYPES}

\begin{abstract}
This work studied the efffect of P omission on the P uptake and on the root length of eight maize genotypes of known P-efficiency response patterns. Two experiments were carried out in growth chambers. In the first one, the seedlings were transplanted to $1.5 \mathrm{~L}$ plastic pots with full strength Steimberg's nutrient solution for seven days. After this period $\mathrm{P}$ was omitted in half of the treatments for 3 days, when the kinectic studies were then initiated by taking $10 \mathrm{ml}$ aliquots every 30 minutes during 8 hours. The second experiment followed the
\end{abstract}


same methodology, except where the P omission was for 6 days. After this period the roots of all treatments were harvested to measure their lengths. These results showed that the omission of $\mathrm{P}$ for 3 days increased the Vmax and the $\mathrm{P}$ influx of all the $\mathrm{P}$-efficient genotypes and two of P-inefficient genotypes. The Km values changed in two genotypes only. This may indicate that increases in Vmax and P influx are mechanisms of response to low P concentration, but they should not be used as parameters to establish differential $P$ response patterns between genotypes. After 6 days of $\mathrm{P}$ omission, the root length incresed in 3 of the four P efficient genotypes. This pattern was not observed with the P-inefficient genotypes, thus suggesting that the differential root growth may be one of the possible mechanisms of $\mathrm{P}$ use efficiency in maize.

Key words: Zea mays L., Phophorus stress, acids soils adaptation, nutritional efficiency, phosphorus absrorption.

Existem numerosas evidências de variações entre e dentre espécies quanto ao uso e acúmulo de fósforo (Furlani et al., 1985; Buso \& Bliss, 1988; Fohse et al., 1988; Rao, 1996; Otani \& Ae, 1996) e do controle genético dessas características (Gabelman, 1976; Whiteaker et al., 1976; Silva, 1990). Essas diferenças genotípicas ajudam a explicar a adaptação de espécies e cultivares às diversas condições de estresse ambiental e formam a base genética para programas de melhoramento.

A eficiência para $\mathrm{P}$ compreende a eficiência de aquisição ou capacidade superior de adquirir $P$ do meio ambiente e o uso eficiente do P, ou seja, a capacidade superior de converter $\mathrm{P}$ em biomassa ou produção. Diversos mecanismos morfológicos, fisiológicos e bioquímicos já foram apontados para explicar diferenças genotípicas quanto à eficiência para fósforo, dentre eles diferenças na absorção de fósforo pelas plantas (modificação das características morfológicas do sistema radicular, aumento da eficiência dos mecanismos fisiológicos de absorção, modificações químicas na interface solo-raiz, mudanças bioquímicas sob deficiência e associação com micorrizas).

Modificações no crescimento e arquitetura de raízes têm sido apontadas como uma importante resposta à deficiência de fósforo no meio (Raghothama, 1999). Caradus (1980), trabalhando com dez espécies de gramíneas e onze de leguminosas, verificou que o grupo das gramíneas pareceu ser mais tolerante a baixos níveis de fósforo que o das leguminosas. As gramíneas apresentaram maior comprimento de sistema radicular, raízes mais finas e pêlos radiculares mais longos, além de dividir o fósforo entre raiz e parte aérea na mesma proporção relativa, independente do nível de fósforo no solo. Segundo o autor, a maior eficiência das gramíneas poderia ser explicada por diferenças na morfologia do sistema radicular, na absorção de fósforo por unidade de raiz e na concentração de fósforo no sistema radicular. Yan et al. (2001) obtiveram boa correlação entre parâmetros de arquitetura de raiz e eficiência para $\mathrm{P}$ em feijão e arroz. Em experimentos conduzidos em areia, esses autores verificaram que os genótipos mais eficientes de arroz e de feijão tenderam a apresentar sistema radicular mais superficial, indicados por maiores ângulos horizontais de inserção de raízes e maior distribuição de raízes nas camadas mais superficiais do meio de crescimento. Gahoonia et al. (1998) e Gahagoonia \& Nielsen (2001), trabalhando com aveia e cevada, observaram que o aumento do crescimento de pêlos radiculares, em condições de baixa disponibilidade de P, foi importante no aumento da absorção de P. Schenk \& Barber (1979) observaram que híbridos de milho apresentavam diferenças quanto à absorção de $\mathrm{P}$, sendo esta atribuída a diferenças no 
Km e Cmin. Alves et al. (1998) verificaram que o híbrido BR 201, eficiente para P, apresentou maiores valores de Vmax, em relação a outros híbridos ineficientes.

A absorção de fósforo pelas raízes é o resultado da interação das características morfológicas e fisiológicas das raízes, da rizosfera imediatamente adjacente ao sistema radicular e de fatores de solo que determinam o fluxo de nutrientes para a interface solo-raiz. Quando o acesso da raiz ao nutriente é um fator limitante, as características morfológicas podem ser consideradas críticas e a eficiência do mecanismo fisiológico de absorção pode ser de importância secundária. Entretanto, quando a chegada de íons à superfície radicular não é limitante, os fatores fisiológicos podem ser decisivos.

Neste trabalho, estudou-se o efeito da omissão de fósforo no meio de cultura nas características fisiológicas de absorção de $\mathrm{P}$ e no comprimento de raízes de genótipos de milho previamente classificados como eficientes e ineficientes para $P$.

\section{Material e Métodos}

Foram conduzidos dois experimentos, com oito genótipos de milho previamente caracterizados, em condições de campo, na Embrapa Milho e de Sorgo, quanto à eficiência para fósforo: quatro ineficientes - HS 64x20, HS 20x22, HS 64×724, HS $22 \times 16$ - e quatro eficientes - BRS 3060, HS $723 \times 36$, BR 201, HS 20x723.

As sementes foram germinadas em rolos de papel toalha, colocados em vasos contendo água deionizada, continuamente arejada, em casa de vegetação. Após a emergência, as plântulas foram selecionadas quanto à uniformidade e transplantadas para recipientes de plástico contendo 13,5 litros de solução nutritiva de Steimberg, pH 5,5, modificada por Foy et al. (1967). O fósforo foi adicionado na forma de $\mathrm{NaH}_{2} \mathrm{PO} 4$, na dose $0,1 \mathrm{mM}$. Cada híbrido foi colocado em dois recipientes individuais contendo 24 plantas. A solução foi trocada a cada dois dias e a aeração mantida constante.

Sete dias após o transplante, o fósforo foi retirado de metade das bandejas. Após três dias de omissão de fósforo, realizou-se a cinética de absorção de fósforo. Nos dois dias que antecederam a execução da cinética, duas plântulas foram transferidas para vasos de plástico com capacidade para 1,5 L, contendo as mesmas soluções. Estes vasos foram transferidos para câmara de crescimento, ajustada para as seguintes condições : fotoperíodo de 12 horas, temperatura diurna / temperatura noturna $26^{\circ} \mathrm{C}$ e $18^{\circ} \mathrm{C}$, respectivamente, umidade relativa diurna $72 \%$ e irradiância de $540 \mu \mathrm{Em}^{-2} \mathrm{~s}^{-1}$.

$\mathrm{Na}$ manhã do dia em que se realizou a cinética, as plantas foram transferidas para solução de estabilização contendo $15 \mu \mathrm{M}$ de fósforo e 50 $\mu \mathrm{M}$ de cálcio, para que o sistema atingisse as condições de estado estacionário da absorção, requeridas para a aplicação do modelo cinético (Epstein \& Hagen, 1952) por uma hora e meia. Ao término deste período, as plântulas foram transferidas para a solução de cinética, idêntica à solução de estabilização, iniciando-se a retirada de alíquotas de $10 \mathrm{ml}$ de cada vaso, a cada 30 minutos, durante 8 horas. Essas alíquotas foram congeladas imediatamente para dosagem posterior do fósforo. Os vasos foram pesados antes e após o início e fim da cinética, para estimar a água perdida por evapotranspiração.

A dosagem de fósforo na solução de cinética foi realizada por sistema de injeção em fluxo ("Flow Injection Analysis"-FIA).

Terminada a cinética de absorção, as plantas foram divididas em raiz e parte aérea, sendo as raízes lavadas e secadas com papel-toalha. O material vegetal foi secado em estufa de circulação forçada de ar, a $75^{\circ} \mathrm{C}$, até atingir peso constante, determinando-se, em seguida, os pesos de matéria seca.

Com base nos dados obtidos, os parâmetros cinéticos Km e Vmax foram calculados conforme 
procedimento proposto por Claassen \& Barber (1974), utilizando-se o processo gráfico matemático descrito por Ruiz (1985). Pela conjugação dos valores de Vmax e Km na equação de Nielsen e Barber (1978), I = Vmax . C/Km + C, calculou-se a taxa de influxo de $\mathrm{P}$ para a concentração externa de $15 \mu \mathrm{M}$.

No segundo experimento, utilizaram-se sementes dos mesmos oito genótipos de milho; após a germinação, as plântulas foram selecionadas quanto à uniformidade e transplantadas para recipientes contendo solução nutritiva de Steinberg, pH 5,5. Sete dias após o transplante, o fósforo foi omitido na metade dos recipientes. Seis dias após a omissão do fósforo, as plântulas dos tratamentos com e sem omissão de fósforo foram coletadas e congeladas, para avaliação do comprimento total do sistema radicular, usando-se o software SIARCS (Crestana et al., 1994). Após a obtenção dos dados de comprimento radicular, as raízes foram secadas em estufas, a $75^{\circ} \mathrm{C}$, para determinação do peso de matéria seca.

\section{Resultados e Discussão}

A disponibilidade de $\mathrm{P}$ em solos tropicais é, geralmente, muito baixa, variando na faixa de micromolar, muitas vezes menor que alguns micronutrientes. Conseqüentemente, as plantas desenvolvem diversos mecanismos adaptativos para contornar baixa disponibilidade, dentre eles modificações na arquitetura e crescimento de raiz, aumento na produção de fosfatases e Rnases, alteração na atividade de diversas enzimas na rota glicolítica e aumento na taxa de absorção de P (Muchhal \& Raghothama, 1999). Essas modificações podem corresponder apenas a uma resposta primária adaptativa das plantas à condição de estresse ou, dependendo da sua intensidade, conferir adaptação diferencial entre espécies ou mesmo entre genótipos de uma mesma espécie.
A
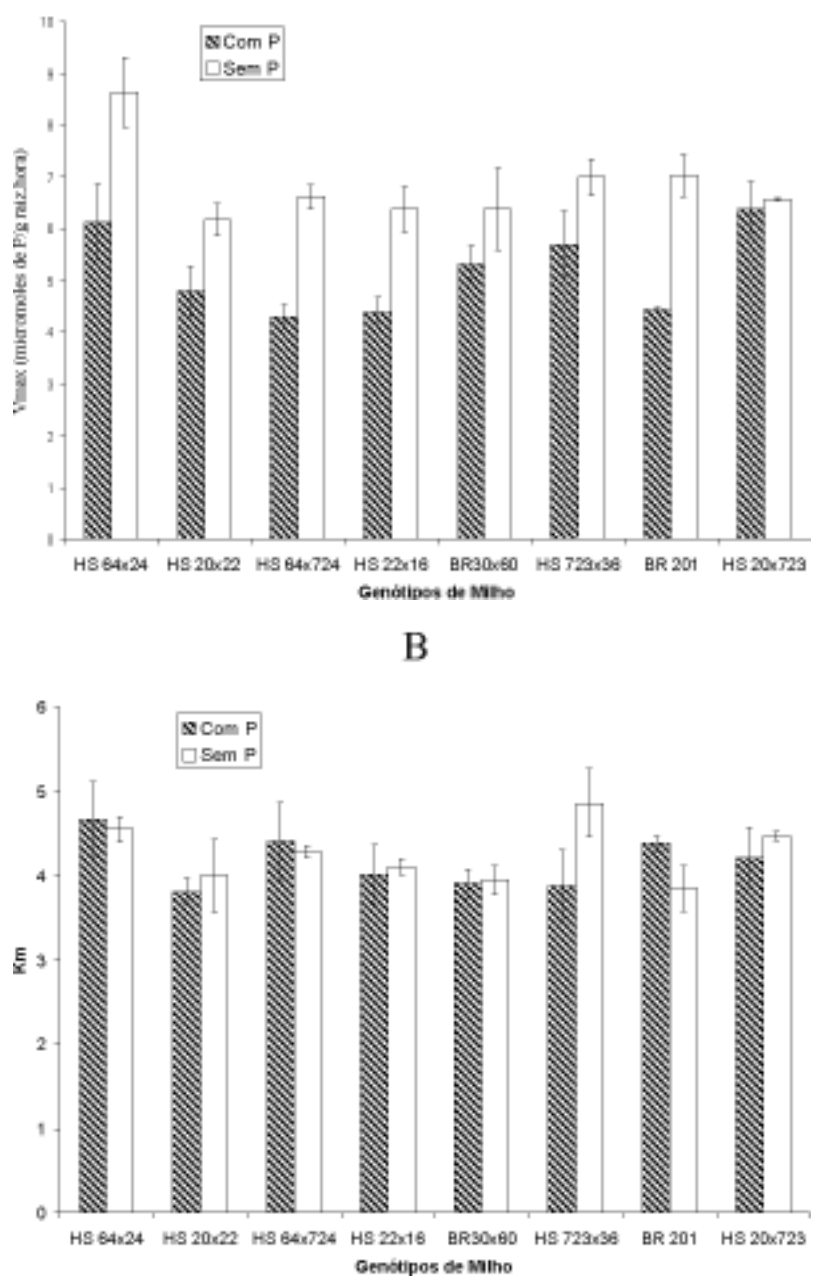

FIGURA 1. Velocidade máxima de absorção de fósforo (Vmax) (A) e Constante de Michaelis (Km) (B) de quatro genótipos de milho ineficientes (HS $64 \times 20$, HS 20x22, HS 64x724, HS 22x16) e quatro eficientes para fósforo (BRS 3060, HS 723x36, BR 201, HS 20x723), após três dias de omissão de fósforo na solução nutritiva.

A omissão de fósforo na solução nutritiva por três dias aumentou significativamente a velocidade máxima de absorção de fósforo (Vmax) em seis genótipos de milho, quatro ineficientes e dois eficientes para $\mathrm{P}$ (Figura 1). Esse aumento chegou a 58\% no BR 201 (eficiente) e a 53\% no HS 64x724 (ineficiente). Comportamento semelhante foi verificado 
para a taxa de influxo, com aumentos de $62 \%$ e $55 \%$, para o BR 201 e HS 64x724, respectivamente (Figura 2). O Km(Constante de Michaelis), que mede a afinidade entre o íon fosfato e o seu transportador, foi significativamente modificado pela omissão de fósforo na solução nutritiva em apenas dois genótipos (Figura 1). No BR 201, houve pequena redução de $12 \%$ e no HS $723 \times 36$, aumento de $25 \%$. Assim, verifica-se que o aumento na taxa de influxo com a omissão de $\mathrm{P}$ no meio de cultivo em seis dos genótipos estudados foi devido ao aumento em Vmax e não a mudanças no $\mathrm{Km}$. Resultados semelhantes foram obtidos em milho, por Anghinoni \& Barber (1980) e Alves et al. (1998), cevada (Drew et al., 1984), soja (Martinez et al., 1993) e células de tabaco (Shimogawara \& Usuda, 1995).

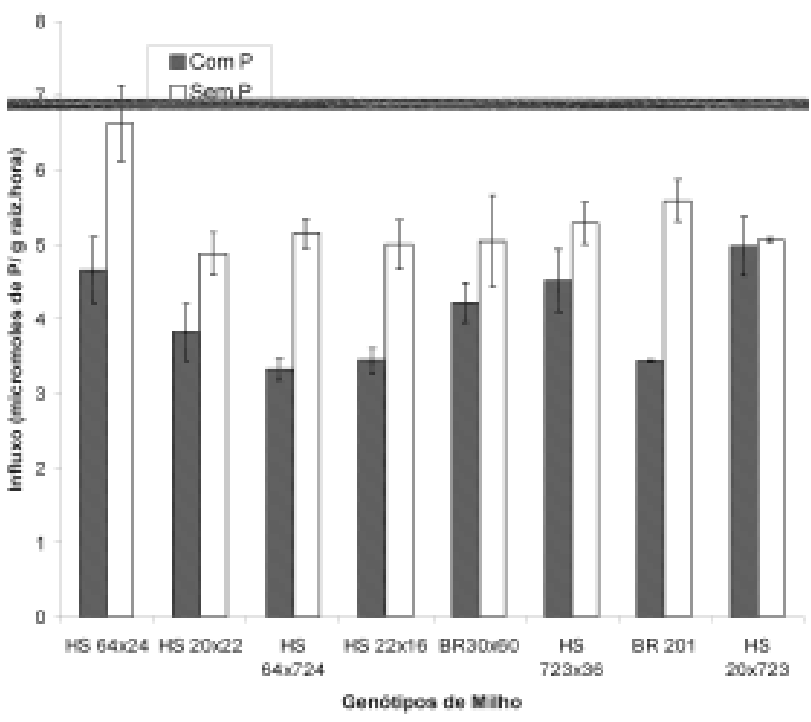

FIGURA 2. Taxa de influxo de fósforo de quatro genótipos de milho ineficientes (HS 64×20, HS 20x22, HS 64x724, HS 22×16) e quatro eficientes para fósforo (BRS 3060, HS 723x36, BR 201, HS 20x723), após três dias de omissão de fósforo na solução nutritiva.

As plantas apresentam a capacidade de manter constante, dentro de certos limites, a concentração citoplásmica de íons com $\mathrm{N}, \mathrm{P}, \mathrm{Ke} \mathrm{Cl}$, apesar das grandes variações no suprimento externo desses íons (Gass \& Siddqi, 1984). Em plantas superiores, o Pi citoplásmico é mantido relativamente constante, durante curtos períodos de deficiência de $\mathrm{P}$, às expensas do Pi vacuolar, o qual é rápida e significativamente reduzido (Bieleski, 1973; Alves, 1994; Mimura et al., 1996). Pelo menos dois diferentes mecanismos são apontados para manter a homeostase de Pi, um operando em nível celular e outro envolvendo diferentes órgãos, provavelmente regulado por sinal proveniente da parte aérea (Raghothama, 1999). Segundo Lee (1982), mudanças nos valores de Vmax e Km representam uma das primeiras modulações das plantas em resposta à redução do suprimento de nutrientes e, geralmente, ocorrem antes da taxa de crescimento ser afetada. Diversos trabalhos demonstram o aumento da absorção de Pi pelas raízes e culturas de células em resposta a deficiência de P (Drew et al., 1984, Shimogawara \& Usuda, 1995, Alves, 1998). Em células cultivadas de tabaco, o aumento na absorção de Pi após estresse de $\mathrm{P}$ foi atribuído ao maior número de transportadores de Pi de alta afinidade (Shimogawara \& Usuda, 1995). Recentemente, Muchhal \& Raghothama (1999) demonstraram que as plantas aumentam sua capacidade de absorver Pi durante períodos de estresse de $\mathrm{P}$ devido à síntese de moléculas transportadoras adicionais.

Apesar do aumento na Vmax e na taxa de influxo de $\mathrm{P}$ em seis dos oito genótipos avaliados, não houve correlação entre eficiência para $P$ e essas características, visto que os dois genótipos que não apresentaram modificações significativas são eficientes para $P$. Conclui-se que aumento na Vmax e na taxa de influxo de $\mathrm{P}$ com a omissão de $\mathrm{P}$ no meio de cultivo é um mecanismo geral de resposta das plantas à deficiência de $\mathrm{P}$, mas que não confere eficiência diferencial entre genótipos de milho.

A omissão de fósforo na solução nutritiva, por seis dias, aumentou significativamente o comprimento radicular em três dos genótipos eficientes 
para fósforo (Figura 3). No híbrido triplo BRS 3060, o aumento do comprimento do sistema radicular foi de $112 \%$, no híbrido duplo BR 201, foi de $61 \%$ e, no híbrido simples HS 20x723, foi de 55\%. Nos genótipos ineficientes para $\mathrm{P}$, não houve modificação significativa dessas características, indicando que o crescimento diferencial do sistema radicular pode ser um dos possíveis mecanismos da eficiência para fósforo em milho.

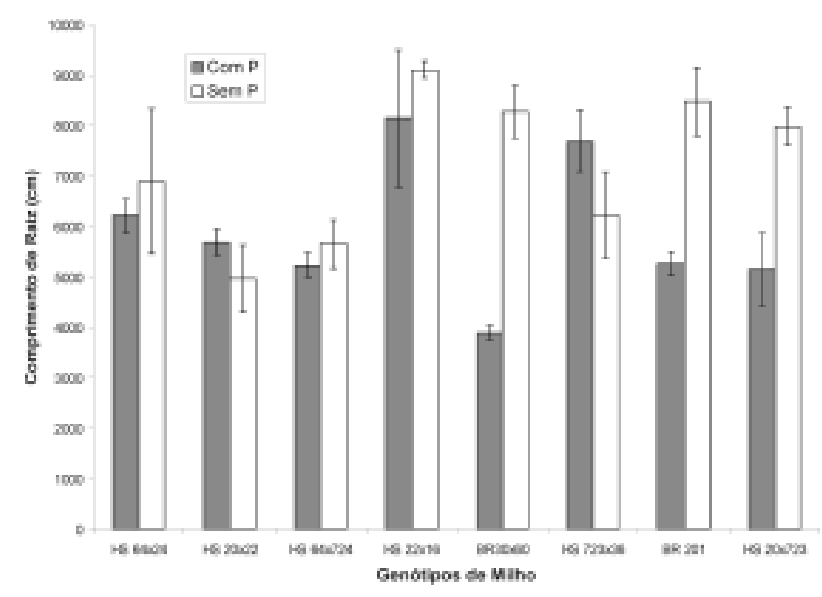

FIGURA 3. Comprimento do sistema radicular de quatro genótipos de milho ineficientes (HS 64x20, HS 20x22, HS 64x724, HS 22x16) e quatro eficientes para fósforo (BRS 3060, HS 723x36, BR 201, HS 20x723), após seis dias de omissão de fósforo na solução nutritiva.

Modificações no crescimento e arquitetura de raízes têm sido apontadas por diversos autores como resposta às condições de baixa disponibilidade de P (Bates et al., 2000; Yan et al., 2001). Isso aumenta o volume de solo explorado pelas raízes, facilitando a absorção de P, principalmente em solos argilosos altamente intemperizados.

Os genótipos estudados neste experimento foram selecionados em um latossolo vermelho-escuro distrófico, argiloso e com alta capacidade de sorção de P. Esse sítio de seleção provavelmente favorece mecanismos que facilitem a difusão de $\mathrm{P}$ no solo, como maior crescimento radicular, raízes mais finas, maior presença de pêlos radiculares, associação com micorrizas, dentre outros. Assim, essas características ainda não contempladas deverão ser avaliadas em experimentos futuros.

\section{Conclusões}

Aumentos na velocidade máxima de absorção de fósforo (Vmax) e na taxa de influxo de P, com a omissão de $P$ no meio de cultivo, é um mecanismo geral de resposta das plantas à deficiência de $\mathrm{P}$, mas não confere eficiência diferencial entre genótipos de milho;

O crescimento diferencial do sistema radicular é um dos mecanismos de eficiência para fósforo em milho.

\section{Literatura Citada}

ALVES, V.M.C.; NOVAIS, R.F.; OLIVEIRA, M.F.G.; SANT'ANNA, R. Cinética e translocação de fósforo em híbridos de milho submetidos a duas doses de fósforo. Pesquisa Agropecuária Brasileira, Brasília, v.33, p.1047 - 1052, 1998.

ALVES, V.M.C. Frações de fósforo, de açúcares solúveis totais e de nitrogênio em quatro híbridos de milho submetidos à omissão e ao ressuprimento de fósforo. 1994. 106 f. Tese (Doutorado em Solos e Nutrição de Plantas) - Universidade Federal de Viçosa, Viçosa.

ANGHINONI, I.; BARBER, S.A. Phosphorus influx and growth characteristics of corn roots as influenced by phosphorus supply. Agronomy Journal, Madison, v.72, p.685 - 688, 1980.

BIELESKI, R.L. Phosphate pools, phosphate transport, and phosphate availability. Annual Review of Plant Physiology, Palo Alto, v.24, p.225-252, 1973.

BUSO, G.S.C.; BLISS, F.A. Variability among lettuce cultivars grown at two levels of available 
phosphorus. Plant and Soil, The Hague, v.111, p.67, 1988.

CARADUS, J.R. Distinguishing between grass and legume species for efficiency of phosphorus use. New Zealand Journal of Agricultural Research, Wellington, v.23, p.75-81, 1980.

CLAASSEN, N.; BARBER, S.A. A method for characterizing the relation between nutrient concentration and flux into roots of intact plants. Plant Physiology, Rockville, v.54, p.564-568, 1974.

CRESTANA, S.; GUIMARÃES, M.F.; JORGE, L.A.C.; RALISCH, R.; TOZZI, C.L.; TORRE, A.; VAZ, C.M.P. Avaliação da distribuição de raízes no solo auxiliada por processamento de imagens digitais. Revista Brasileira de Ciência do Solo, Campinas, v.18, p.365-371, 1994.

DREW, M.C.; SAKER, L.R.; BARBER, S.A.; JENKINS, W. Changes in the kinetic of phosphate and potassium absorption in nutrient-deficient barley roots measured by a solution-depletion technique. Planta, New York, v.160, p.490-499, 1984.

EPSTEIN, E.; HAGEN, C.E. A kinetic study of the absorption of alkali cations by barley roots. Plant Physiology, Palo Alto, v.27, p.457-474, 1952.

FOHSE, D.; CLAASSEN, N.; JUNGK, A. Phosphorus efficiency of plants. I. External and internal $P$ requirement and $P$ uptake efficiency of different plant species. Plant and Soil, The Hague, v.110, p.101-109, 1988.

FOY, C.D.; FLEMING, A. L.; BURNS, G.R.; ARMINGER, W.H. Characterization of differential aluminum tolerance among varieties of wheat and barley. Agronomy Journal, Madison, v.31, p.513$521,1967$.
FURLANI, A.M.C.; BATAGLIA, O.C.; LIMA. Eficiência de linhagens de milho na absorção e utilização de fósforo em solução nutritiva. Bragantia, Campinas, v.44, p.129-147, 1985.

GABELMAN, W.H. Genetic potentials in nitrogen, phosphorus and potassium efficiency. In: WORKSHOP ON PLANT ADAPTATION TO MINERAL STRESS IN PROBLEM SOILS, 1976, Beltsuille. Procedings... Ithaca: Cornell University, 1976, p.205-212. Editecl by M. J. Wright.

GAHOONIA, T.S.; NIELSEN, N.E Direct evidence on participation of root hairs in phosphorus $\left({ }^{32} \mathrm{P}\right)$ uptake from soil. Plant and Soil, The Hague, v.198, p.147-152, 1998.

GAHOONIA, T.S.; NIELSEN, N.E. Measuring and modeling phosphorus uptake by root hairs. In: HORST et al. (Eds). Plant Nutrition: Food security and sustainability of agro-ecosystems through basic and applied research. Dordrecht: Kluwer Academic, 2001. p. 534-535.

GLASS, A. D. M.; SIDDQI, M.Y. The control of uptake rates in relation to the inorganic composition of plantas. In: TINKER, P.B.; LAÜCHLi, A. (Eds). Advances in Plant Nutrition. New York: Praeger, 1984. v.1, p.103-147.

LEE, R.B. Selectivity and kinetics of ion uptake by barley plant following nutrient deficiency. Annals of Botany, London, v.50, p. 429-449, 1982.

MARTINEZ, H.E.P.; NOVAIS, R.F.; RODRIGUES, L.A.; SACRAMENTO, L.V.S. Comportamento de variedades de soja cultivadas em diferentes doses de fósforo: I. Cinética de absorção de fósforo e ajustes morfológicos da planta. Revista Brasileira de Ciência do Solo, 17:231238, 1993. 
MIMURA, T.; SAKANO, K.; SHIMMEN, T. Studies on the distribution, retranslocation and homeostasis of inorganic phosphate in barley leaves.

Plant and Cell Environmental, Oxford, v.19, p.311-320, 1996.

MUCHHAL, U.S.; RAGHOTHAMA, K.G. Transcriptional regulation of plant phosphate transporters, Proceedings of the National Academy of Science, Washington, v.96, p.5868-5872, 1999.

NIELSEN, N.E.; BARBER, S.A. Differences among genotypes of corn in the kineticsof P uptake. Agronomy Journal, Madison, v.70, p.695-698, 1978.

OTANI, T.; AE, N. Phosphorus (P) uptake mechanisms of crop grown in soil with low $P$ status. I. Screening of crops for efficient P uptake. Soil Science and Plant Nutrition, Tokyo, v.42, p.155163, 1996.

RAGHOTHAMA, K.G. Phosphate acquisition. Annual Review of Plant Physiology and Plant Molecular Biology, Palo Alto, v.50, p.665-693, 1999.

RAO, I. M.; BORRERO, V.; RICAURTE, J.; GARCIA, R.; AYARZA, M.A. Adaptive attributes of tropical forage species to acid soils. II. Differences in shoot and root growth responses to varying phosphorus supply and soil type. Journal of Plant Nutrition, New York, v. 19, p.323-352, 1996.

RUIZ, H. A. Estimativa dos parâmetros cinéticos Km e Vmáx por uma aproximação gráfico-matemática. Revista Ceres, Viçosa, v.32, n. 179, p. 79-84, 1985
SCHENK, M.K.; BARBER, S.A. Root characteristics of corn genotypes as related to $\mathrm{P}$ uptake. Agronomy Journal, Madison, v.71, p.921926, 1979.

SHIMOGAWARA, K.; USUDA, H. Uptake of inorganic phosphate by suspension - cultured tobacco cells: kinetics and regulation by Pi starvation. Plant and Cell Physiology, Tokyo, v.36, p.341-351, 1995.

SILVA, A.E. Inheritance studies of phosphorus acquisition and utilization efficiency in maize (Zea mays L.) 149f. Thesis (Doctor of Phylosophy Plant Breeding and Plant Genetics) - University of Wisconsin, Madison.

WHITEAKER, G.; GERLOFF, G.C.; GABELMAN, W.H \& LINDGREN, D. Intraspecific differences in growth of beans at stress levels of phosphorus. Journal of American Society for Horti cultural Science, Geneva, v.101, p.472475, 1976.

YAN, X.; LIAO, H.; CAO, A.; HE, Y. The role of root architecture in $\mathrm{P}$ acquisition efficiency of efficiency of different root systems: a case study with common bean and rice. In: HORST et al. (Eds). Plant Nutrition: Food security and sustainability of agro-ecosystems through basic and applied research. Dordrechet Kluwer Academic Publishers, 2001. p. 90-591. 